\title{
Os contenciosos comerciais e os principais casos de retaliação do Brasil à prática de subsídios agrícolas na Organização Mundial de Comércio
}

\author{
Trade disputes and the main cases of Brazil' retaliation based on \\ agricultural subsidies at the World Trade Organization
}

Flávio Marcelo Rodrigues Bruno ${ }^{\mathrm{I}^{*}}$ André Filipe Zago de Azevedo ${ }^{\mathrm{I}}$ Angélica Massuquetti ${ }^{\mathrm{I}}$

\section{RESUMO}

O artigo aborda a adoção de medidas de retaliação, através de direitos compensatórios, à prática de subsídios no comércio agrícola internacional, por meio da análise da evolução das diferenças comerciais submetidas à Organização Mundial de Comércio (OMC). Os resultados revelam que os Estados Unidos da América e a União Europeia são os membros que mais sofrem medidas de retaliação na OMC, em razão dos impactos de suas políticas de subsídios ao setor agrícola. Além disso, houve uma queda nos contenciosos comerciais submetidos à apreciação da OMC, especialmente em matéria de direitos compensatórios em relação ao setor agrícola.

Palavras-chave: subsídios agrícolas, direitos compensatórios, OMC.

\section{ABSTRACT}

This article analyzes the adoption of retaliatory measures, based on countervailing measures, on the practice of subsidies in international agricultural trade, by means of a survey on the evolution of trade differences submitted to the World Trade Organization (WTO). It was possible to identify the United States and the European Union as the members who most suffer from retaliation in the WTO, because of the impacts of their policies on subsidies on the agricultural sector. However, there was a drop in trade disputes submitted to WTO, especially with regard to countervailing measures related to the agricultural sector.

Key words: agricultural subsidies, countervailing measures, WTO.

\section{INTRODUÇÃO}

Do total de 234 disputas comerciais submetidas à Organização Mundial do Comércio (OMC), no período entre 2000 e 2010, há o registro de 71 casos em matéria de direitos compensatórios, isto é, os contenciosos sobre essa matéria equivalem a 30\% do total de contenciosos comerciais resolvidos ou em disputa no órgão. Relacionados à agricultura, existem 77 casos registrados, o equivalente a $32 \%$ dos contenciosos registrados na OMC, sendo que 21 deles versam sobre direitos compensatórios. No entanto, há uma diminuição das disputas comerciais em relação ao setor agrícola, sobretudo em se tratando de direitos compensatórios, embora essa queda acompanhe a própria diminuição das diferenças comerciais submetidas à OMC (WTO, 2011).

Os Estados Unidos da América (EUA) e a União Europeia (UE) são os membros que mais sofrem medidas de retaliação na OMC, em razão dos impactos de suas políticas de subsídios ao setor agrícola. EUA e UE ostentam a posição de economias que mais usam formas de subsídios à produção e à exportação e foram derrotadas na OMC em dois casos emblemáticos para o setor e que envolviam o Brasil. É sob esse contexto que a questão dos subsídios concedidos à agricultura tem sido muito discutida na atual Rodada Doha de negociações comerciais da OMC, sendo o Brasil uma força econômica contrária a essa prática, prejudicial ao equilíbrio do comércio mundial.

O presente artigo analisa a adoção de medidas de retaliação no exercício de direitos compensatórios à prática de subsídios no comércio agrícola internacional, no período 2000-2010. A utilização dos subsídios, em especial os concedidos à agricultura, constitui-se em prática protecionista, que

'Programa de Pós-graduação em Economia, Universidade do Vale do Rio dos Sinos (UNISINOS), 93022-000, São Leopoldo, RS, Brasil. E-mail: flavio.bruno@msn.com.*Autor para correspondência. 
interfere de modo negativo no comércio internacional e a retaliação por meio dos direitos compensatórios é uma forma de controle ou repressão a essa prática. A pesquisa foi desenvolvida a partir da metodologia de pesquisa bibliográfica e do levantamento de dados acerca da evolução das diferenças comerciais submetidas à OMC.

O artigo está dividido em quatro seções, além desta introdução. A segunda seção aborda os subsídios no comércio internacional e os direitos compensatórios na OMC. A terceira seção analisa a evolução das diferenças comerciais no Sistema de Solução de Controvérsias (SSC) da OMC, em especial os relacionados aos direitos compensatórios e ao setor agrícola. Na quarta seção, são relatados dois casos mais recentes e notórios, submetidos e decididos pela OMC, relacionados à prática de subsídios por parte dos EUA e da UE e que tem no Brasil o principal beneficiado das decisões. Por fim, a quinta seção apresenta as conclusões do estudo.

Subsídios e os direitos compensatórios na OMC

O atual cenário mundial do comércio entre nações busca a liberalização comercial e a ampla interação entre as economias, que somente serão possíveis se houver cooperação entre os países, aplicação da regulamentação internacional e livre acesso aos mercados. Nesse sentido, sempre existirão conflitos de interesses nacionais, sujeitos às regras comerciais reconhecidas internacionalmente, o que leva à necessidade de um mecanismo de harmonização através da mediação e da conciliação ou da tomada de decisões, calcada na regulamentação do comércio internacional (LAFER, 1998). O SSC da OMC assume fundamental importância, pois é a entidade responsável pelo encaminhamento da negociação, pela tentativa de conciliação e pelo exame das reclamações decorrentes das relações comerciais internacionais, travadas entre os paísesmembros da OMC (WTO, 2011).

Para haver equilíbrio no comércio internacional, é preciso que as regras existentes na OMC sejam compartilhadas por todos e aqueles que se sintam prejudicados, para que tenham a possibilidade de recorrer à revisão do regulamento ou das ações de determinada nação que se beneficia das regras ou da falta de reconhecimento ou aplicação destas em suas ações (BECHARA \& REDENSCHI, 2001). O SSC é fruto dessa concepção, em que um conflito comercial entre nações é resolvido com base nas normas estabelecidas pela OMC e com vistas à liberalização do comércio internacional. Representa o instrumento utilizado pelos países-membros da
OMC, quando acreditam que outras nações estão violando ou não considerando as regras que regem o comércio mundial. Em casos nos quais os prejuízos não cessam mesmo com a decisão da OMC, no sentido de suspensão das ações prejudiciais, o país reclamante solicita a autorização para a adoção de retaliações comerciais que recairão sobre a nação demandada (BECHARA \& REDENSCHI, 2001).

Geralmente, as controvérsias surgem quando uma nação adota uma determinada política ou prática comercial considerada como violadora dos acordos de comércio internacional, regulamentados pela OMC, como é o caso da prática de subsídios domésticos à produção e dos subsídios à exportação. $\mathrm{O}$ conceito de subsídios trazido pelo Acordo sobre Subsídios e Medidas Compensatórias (ASMC) da OMC se constitui na única definição legal acordada internacionalmente. Os subsídios são uma forma de intervenção governamental nas atividades econômicas, caracterizada por transferências de recursos a produtores ou consumidores, objetivando a garantia ou suplementação de suas rendas ou, ainda, a redução dos custos de produção.

A retaliação por meio dos direitos compensatórios é a forma de controle ou repressão da prática de subsídios por parte das economias encontrada pela OMC. Ressalte-se a existência de uma nação prejudicada, que figura como reclamante, e uma nação que seria a beneficiária de tais políticas ou práticas, que figura como parte demandada. Mas quaisquer outros países que se julgarem interessados na disputa comercial instaurada podem requerer sua participação na condição de terceiros interessados na disputa, desde que comprovados os reflexos do caso sobre sua economia (WTO, 2011). Medidas anti-subsídios, configuradas por sobretaxas aplicadas a produtos de determinada origem, que sejam exportados com outorga de subsídio no país exportador e causando prejuízo ao país importador, possuem o efeito de neutralizar os subsídios.

Não restam dúvidas de que os subsídios distorcem preços, realocam recursos e alteram a quantidade de produtos e serviços produzidos e consumidos em uma economia. Outro efeito comum é a depreciação artificial dos preços internacionais, o que prejudica sobremaneira os interesses dos grandes produtores. COSTA \& BURNQUIST (2006), por exemplo, estimaram que a redução de $1 \%$ no nível do subsídio da UE aumentaria o preço de exportação do açúcar europeu em 0,22\%. Essa distorção justifica a regulação da prática de subsídios pela OMC, tanto com o tratamento referido no ASMC como no Acordo sobre a Agricultura (AsA) (DANTAS, 2009). 
Os efeitos internacionais dos subsídios são proporcionais ao tamanho da economia do país que o concede, ou seja, políticas estadunidenses ou europeias têm o potencial de ser muito mais distorcivas tanto em decorrência da dotação orçamentária dos respectivos governos, como devido ao tamanho dos seus mercados (DANTAS, 2009). Isso se demonstra à medida que os subsídios concedidos pelos Estados-membros da Organização para a Cooperação e Desenvolvimento Econômico (OCDE) têm causado dano significativo às economias dos países em desenvolvimento, os quais seriam os maiores beneficiários com a sua redução (DURAIAPPAH, 2003).

A evolução das diferenças comerciais na OMC e os direitos compensatórios

De acordo com os registros da OMC em relação à evolução das diferenças comerciais submetidas ao órgão, é possível identificar uma redução das controvérsias que são levadas ao SSC, haja vista que os registros de 34 disputas, em 2000, e de 20, em 2006, sofrem uma queda para 14, em 2009, e 17 casos, em 2010, como mostra a tabela 1.

No entanto, também é evidente a crescente importância em relação aos casos que envolvem o exercício de direitos compensatórios, pois, em 2000, das 34 controvérsias submetidas ao órgão, apenas sete tratavam do tema. Para o ano de 2009, de 14 disputas comerciais, 13 tratavam de direitos compensatórios. Merece destaque o setor agrícola, tanto em relação ao total de disputas comerciais quanto em relação às controvérsias sobre direitos compensatórios. Em

Tabela 1 - Evolução das diferenças comerciais na OMC: total de casos contenciosos envolvendo direitos compensatórios e em relação à agricultura, 2000-2010 (com referência ao total de casos registrados na OMC).

\begin{tabular}{lllll}
\hline & & & & \\
Ano & ----Disputas comerciais---- & & \\
& DS* & DC** & DS* & DC** \\
\hline 2000 & 34 & 7 & 8 & 0 \\
2001 & 23 & 4 & 11 & 0 \\
2002 & 37 & 7 & 14 & 3 \\
2003 & 26 & 6 & 10 & 2 \\
2004 & 19 & 6 & 4 & 2 \\
2005 & 12 & 2 & 6 & 1 \\
2006 & 20 & 9 & 7 & 3 \\
2007 & 13 & 5 & 6 & 2 \\
2008 & 19 & 7 & 3 & 2 \\
2009 & 14 & 13 & 6 & 6 \\
2010 & 17 & 5 & 2 & 0 \\
Total & 234 & 71 & 77 & 21 \\
\hline
\end{tabular}

Fonte: Elaboração dos autores a partir de dados da WTO (2011). Notas: (*) DS - Dispute settlement (solução de controvérsias); (**) DC - Direitos compensatórios.
2000, do total de 34 disputas comerciais, oito eram relativas ao setor e, destas, nenhuma tratava de direitos compensatórios no comércio agrícola internacional. Para o ano de 2009, das 14 disputas comerciais submetidas ao SSC da OMC, seis eram relacionadas ao setor e todas versavam sobre a retaliação por meio de direitos compensatórios.

Do total de 234 disputas comerciais submetidas à OMC no período entre 2000 e 2010, em matéria de direitos compensatórios, há o registro de 71 casos, isto é, os contenciosos sobre essa matéria equivalem a $30 \%$ do total de contenciosos comerciais resolvidos ou em disputa no SSC. Os EUA envolveram-se em 108 casos de 2000 a 2010. Destes, a nação atua diretamente como parte reclamante em 37 disputas e como parte demandada em 71 casos. As disputas que envolvem direitos compensatórios somam 42 casos e, em 32, os EUA são a parte demandada, como mostra a Tabela 2. Em matéria de direitos compensatórios, os EUA são o país-membro que mais figura como demandado e responde por $60 \%$ do total de contenciosos.

Este país é seguido de UE e China, demandadas em 12 casos. Para o período analisado, a UE envolveu-se em 77 disputas e, destas, em 35 casos o bloco é parte reclamante e figura como parte demandada em 42. Do total de casos que envolvem a UE como parte direta, o equivalente a $36 \%$, ou seja, 28 casos são referentes a direitos compensatórios, sendo que, em apenas 12 deles, o bloco é parte demandada, nos outros 16 casos, atua como reclamante.

Entre os anos de 2000 e 2010, dos 234 casos na OMC, o Brasil figura como parte direta em 24 disputas. A Tabela 3 mostra que o país possui 19 registros como reclamante e em cinco disputas é demandado. Destes 24 contenciosos, 70\% envolvem os EUA e a UE. Nas disputas contra os estadunidenses, o Brasil é reclamante em nove contenciosos para

Tabela 2 - Principais nações envolvidas em contenciosos da OMC, em matéria de direitos compensatórios, 20002010 (porcentagem com referência ao total de casos registrados na OMC).

\begin{tabular}{lcccc}
\hline Países & $\begin{array}{c}\text { Casos } \\
\text { envolvidos }\end{array}$ & $\begin{array}{c}\text { Parte } \\
\text { reclamante }\end{array}$ & $\begin{array}{c}\text { Parte } \\
\text { demandada }\end{array}$ & $\%$ \\
\hline EUA & 42 & 11 & 32 & 59,2 \\
EU & 28 & 16 & 12 & 39,4 \\
China & 18 & 6 & 12 & 25,4 \\
Canadá & 15 & 12 & 3 & 21,1 \\
República da Coreia & 9 & 7 & 2 & 12,7 \\
México & 8 & 5 & 3 & 11,3 \\
Total de diferenças comerciais submetidas ao SSC da OMC & 71 \\
\hline
\end{tabular}

Fonte: Elaboração dos autores a partir de dados da WTO (2011). 
Tabela 3 - Panorama da participação do Brasil em disputas comerciais na OMC, por ano, por envolvimento como parte e por matéria referente ao contencioso, 2000-2010.

\begin{tabular}{|c|c|c|c|c|}
\hline Ano & DS* & Reclamante & Demandado & Matéria \\
\hline \multirow{9}{*}{2000} & 190 & Brasil & Argentina & Medidas de salvaguarda às importações de tecidos de algodão. \\
\hline & 197 & EUA & Brasil & Medidas relativas aos preços mínimos de importação. \\
\hline & 199 & EUA & Brasil & Medidas que afetam a proteção mediante patentes. \\
\hline & 208 & Brasil & Turquia & Direito antidumping sobre tubos de ferro e aço. \\
\hline & 209 & Brasil & UE & Medidas fitossanitárias que afetam a importação de café. \\
\hline & 216 & Brasil & México & Medidas antidumping sobre transformadores elétricos. \\
\hline & 217 & Brasil & UE & Direitos compensatórios à política de subsídios (Emenda Byrd). \\
\hline & 218 & Brasil & EUA & Direitos compensatórios sobre produtos de aço e carbono. \\
\hline & 219 & Brasil & UE & Medidas antidumping sobre tubos de fundição. \\
\hline \multirow{5}{*}{2001} & 222 & Brasil & Canadá & Direitos compensatórios à prática de subsídios à exportação de aeronaves. \\
\hline & 224 & Brasil & EUA & Elementos de discriminação presentes no Código de Patentes. \\
\hline & 229 & Índia & Brasil & Medidas antidumping sobre bolsas de jute. \\
\hline & 239 & Brasil & EUA & Medidas antidumping sobre silício-metal. \\
\hline & 241 & Brasil & Argentina & Medidas antidumping sobre frango. \\
\hline \multirow{5}{*}{2002} & 250 & Brasil & EUA & Aplicação de impostos sobre as importações de laranja. \\
\hline & 259 & Brasil & EUA & Medidas de salvaguarda sobre importações de aço. \\
\hline & 266 & Brasil & UE & Direitos compensatórios à prática de subsídios à exportação de açúcar. \\
\hline & 267 & Brasil & EUA & Direitos compensatórios à prática de subsídios à produção de algodão. \\
\hline & 269 & Brasil & UE & Medidas fitossanitárias que afetam a importação de frango. \\
\hline 2005 & 332 & UE & Brasil & Medidas que afetam a importação de pneumáticos. \\
\hline 2006 & 355 & Argentina & Brasil & Medidas antidumping sobre resinas. \\
\hline 2007 & 365 & Brasil & EUA & Direitos compensatórios à prática de subsídios à exportação agrícola. \\
\hline 2008 & 382 & Brasil & EUA & Direitos compensatórios à prática de subsídios à produção de laranja. \\
\hline 2010 & 409 & Brasil & UE & Apreensão de medicamentos genéricos. \\
\hline Total & 24 & 19 & 5 & - \\
\hline
\end{tabular}

Fonte: Elaboração dos autores a partir de dados da WTO (2011). Nota: (*) DS - Dispute settlement (solução de controvérsias).

um total de 11. Envolvendo a UE, são seis disputas comerciais, sendo que em cinco a nação brasileira é reclamante. Em matéria de direitos compensatórios, o Brasil é parte envolvida em sete disputas comerciais e, em todos os casos, é parte reclamante. Há a ocorrência de um contencioso, tendo o Canadá como demandado, o mesmo ocorre com a UE e, em cinco casos, o país demandado é os EUA. Dos sete contenciosos, em matéria de direitos compensatórios, em que o Brasil está envolvido, quatro representam um marco na atuação do país em disputas comerciais na OMC, sendo que dois envolvem discussões sobre a prática de subsídios à agricultura (WTO/DS222, WTO/DS266, WTO/DS267 e WTO/DS382).

Dentre os contenciosos de maior discussão atual, em matéria de direitos compensatórios, estão os que envolvem a prática de subsídios no comércio agrícola mundial e que têm como parte reclamante o Brasil: a concessão de subsídios à produção de algodão por parte dos EUA e de subsídios à exportação de açúcar pela política agrícola da UE. A OMC atua em posição contrária à prática de subsídios domésticos à produção e subsídios à exportação e suas decisões exigem que o ASMC e o AsA sejam cumpridos.

Os dados trazidos até o momento permitem a identificação dos EUA e da UE como as economias que mais utilizam subsídios no comércio internacional, em razão da quantidade de casos registrados na OMC que envolvem as duas nações como parte demandada em matéria de direitos compensatórios à prática de subsídios. Em matéria agrícola, ostentam a posição de economias que mais usam formas de subsídios à produção e à exportação e foram derrotadas na OMC em dois casos emblemáticos para o setor, que envolviam o Brasil. Assim, tanto os estadunidenses quanto o bloco europeu são os membros que mais sofrem medidas de retaliação na OMC em razão dos impactos de suas políticas de intervenção governamental protecionistas.

Portanto, a importância de se analisar as principais diferenças comerciais que contrapõem a prática dos subsídios à agricultura na UE e nos EUA está intimamente ligada ao que se demonstrou até o momento com relação à evolução, entre os anos de 2000 e 2010, das disputas comerciais submetidas à OMC. Fundamentalmente, porque as duas potências figuram como os países-membros mais envolvidos em contenciosos comerciais na OMC e também como principais provedores de subsídios, especialmente em relação ao setor agrícola.

É sob esse contexto que os subsídios concedidos à agricultura têm sido discutidos na atual 
Rodada Doha de negociações comerciais da OMC. O Brasil é a principal força econômica contrária a essa prática e atua no exercício do papel de liderança do Grupo Cairns, que vem sendo considerado um ator importante em favor da eliminação dos subsídios no comércio agrícola internacional, principalmente os subsídios domésticos à produção e à exportação. Esses subsídios são prejudiciais às relações comerciais internacionais e compõem as duas práticas combatidas pelo governo brasileiro na disputa comercial do açúcar contra a UE e do algodão contra os EUA.

Os principais casos de retaliação do Brasil à prática de subsídios na UE e nos EUA

No atual cenário econômico mundial, na emergência das discussões entre liberalismo e protecionismo, as discussões sobre a prática de subsídios no comércio internacional e as decisões da OMC sobre o tema, especialmente no âmbito do comércio agrícola mundial, estão em evidência. Ademais, os dois contenciosos no SSC mais importantes sobre o tema para este setor envolvem o Brasil. Com isso, a forte atuação do país no cenário econômico mundial o coloca como ator de papel fundamental na consolidação da Rodada Doha. Para o diretor-geral da OMC, a Rodada Doha encontra barreiras a sua conclusão, justamente pelas indefinições com relação às matérias vinculadas à prática de subsídios no comércio internacional, em especial ao setor agrícola, tendo como principais forças negociadoras os EUA, a UE e o Grupo Cairns, sob a liderança do Brasil (LAMY, 2005).

Merece destaque a atuação da organização, como uma terceira força nesta negociação, pois partiu do grupo uma proposta de redução gradual dos subsídios ao setor, que tem sido uma busca incessante da OMC nas negociações da Rodada Doha. De acordo com o proposto pelo Grupo Cairns, apresentado no ano de 2005, os subsídios à exportação agrícola seriam eliminados em dezembro de 2013.

Conforme já mencionado, EUA e UE figuram não apenas como os países-membros mais envolvidos em contenciosos comerciais na OMC, mas também como os principais provedores de subsídios, em especial no setor agrícola, onde os EUA figuram como demandado por prática de subsídios em sete disputas e a UE em seis casos. É com base nesses dados que se justifica realizar uma breve análise dos dois casos mais relevantes para estas duas economias e que foram submetidos ao SSC, da OMC, que envolvem a concessão de subsídios na atuação destas economias no comércio agrícola internacional.
WTO/DS265 - subsídios da UE à exportação de açúcar Esta disputa comercial envolve três demandas (WTO/DS265, WTO/DS266 e WTO/ DS283). Em setembro de 2002, Austrália e Brasil solicitaram a celebração de consultas à UE em relação à concessão de subsídios às exportações de açúcar. Em março de 2003, a Tailândia também realizou a mesma solicitação sobre o assunto. A Austrália sustentava que a UE concedia subsídios à exportação de açúcar acima do estipulado no compromisso especificado na lista de concessões de subsídios para o bloco europeu, nos termos do AsA. A alegação era de que a Política Agrícola Comum (PAC) europeia estabelecia duas categorias de produção de açúcar, as quais recebiam os montantes de subsídio, e o que era produzido a mais do que o estipulado e suportado pelo mercado interno precisava ser exportado a preços menores do que os praticados no mercado internacional. Ao refino do açúcar também se alegava a concessão de subsídios distorcivos ao comércio, já que o apoio era concedido aos refinadores que se atinham a refinar o açúcar produzido internamente, o que prejudicava o açúcar importado de outras nações produtoras (WTO, 2010a). Os subsídios concedidos à exportação de açúcar ultrapassavam os níveis estipulados pelo compromisso de redução de subsídios à agricultura (WTO, 2010b). A intervenção da PAC no setor garantia um preço elevado para o açúcar produzido dentre as duas categorias previstas, o açúcar que era produzido além dessas categorias não poderia ser comercializado no mercado interno e deveria ser exportado, em razão dos subsídios concedidos a preços inferiores ao custo total de produção. Além disso, os subsídios concedidos pela UE ao setor ultrapassavam os compromissos assumidos perante o AsA. As denominadas "restituições por exportação" cobriam a diferença entre o preço do mercado mundial e os elevados preços do açúcar no mercado interno, permitindo que o excedente fosse exportado a preços inferiores aos praticados no comércio internacional (WTO, 2010b). Já a Tailândia alegou que o regime da PAC sobre o açúcar concedia ao produto importado tratamento inferior e desfavorável em relação ao açúcar produzido no mercado interno. Assim, concedendo tais subsídios, o tornava mais competitivo que o açúcar importado (WTO, 2010d).

Em dezembro de 2003, foi estabelecido um Grupo Especial, pela OMC, para a análise das referidas disputas comerciais. Em outubro de 2004, o Grupo constatou, entre outras questões, que a UE atuava de maneira incompatível com as obrigações assumidas perante o AsA, não comprovando que suas produções não estavam acima dos níveis estipulado 
perante a OMC e que, neste caso, quando um membro exporta um produto agrícola em quantidades que excedem os níveis de seus compromisso, esse membro será tratado como se tivesse concedido subsídios à exportação incompatíveis com o regime da OMC, a menos que demonstre provas do contrário, o que não ocorreu neste caso.

A UE foi parte vencida neste caso, mas entrou em negociação comercial com Austrália, Brasil e Tailândia no sentido de não eliminar as restituições por exportação ao açúcar, mas reduzir os níveis de subsídios concedidos ao setor. Na prática, isso não vem ocorrendo, mas, ao contrário, os níveis de subsídios concedidos ao setor têm sido elevados. Tal situação tem feito com que a OMC repense sua decisão e tem levado os governos de Austrália e Brasil a manifestarem-se no sentido de solicitar direitos compensatórios à prática de subsídios ao açúcar europeu. Esse caso impõe dúvidas quanto à eficácia das decisões do Órgão de Solução de Controvérsias (OSC) e sobre os atuais mecanismos de imposição das decisões do SSC, pela OMC.

A decisão proferida pela OMC, em 2005, foi positiva ao Brasil e às demais nações envolvidas como terceiros interessados. No contencioso, a UE se manifestou em concordância com a aplicação das recomendações da OMC, a qual exige que, na adoção das políticas agrícolas europeias relacionadas a commodity, seja considerado o ratificado no AsA e no ASMC. A decisão proferida é no sentido de eliminação gradual dos subsídios do bloco europeu à exportação da commodity. No entanto, a OMC tem se mostrado preocupada com o caso, pois as medidas tomadas pela UE até o momento ou contradizem suas recomendações ou não levam em consideração a decisão da OMC. Essa situação leva a OMC a uma revisão sobre sua decisão no OSC quanto ao contencioso do açúcar, a partir de uma possível manifestação do governo brasileiro no sentido de requerer a aplicação de medidas de retaliação contra produtos importados do bloco europeu, medidas extensivas aos demais interessados na disputa comercial.

WTO/DS267 - subsídios à produção e à exportação do algodão dos EUA

A demanda, iniciada em setembro de 2002, com pedido de consultas por parte do Brasil, envolveu o questionamento de subsídios concedidos pelos EUA à produção e à exportação de algodão. Foram questionadas, dentre os subsídios específicos, duas categorias à sua prática, sendo a primeira sobre subsídios proibidos e a segunda sobre subsídios recorríveis.

Em março de 2005, o SSC adotou os relatórios do Painel e do Órgão de Apelação. As decisões adotadas no contencioso condenaram amplamente os subsídios estadunidenses, tanto com relação aos subsídios proibidos, como no tocante aos subsídios acionáveis. No que diz respeito aos subsídios proibidos, o Painel e o Órgão de Apelação consideraram que três programas de garantias de crédito à exportação - GSM 102, GSM 103 e SCGP - configuravam subsídios à exportação, aplicados de forma incompatível com os compromissos dos EUA no AsA, da OMC, não somente com relação ao algodão, mas a um conjunto mais amplo de produtos agrícolas. Julgou-se que tais subsídios eram ilegais, tanto de disposições do AsA como do ASMC. Como resultado, os EUA deveriam retirar os subsídios sem demora e pelo prazo máximo de julho de 2005 (WTO, 2010c).

Em relação aos subsídios acionáveis, o Painel e o Órgão de Apelação consideraram que três programas de apoio interno estadunidense - Marketing Loan, Counter-Cyclical Payments e Step 2 - causam prejuízos graves ao Brasil, tendo gerado supressão significativa dos preços do algodão no mercado internacional, em violação ao ASMC. Em decorrência, os EUA deveriam remover os efeitos adversos causados por esses subsídios ou retirá-los até setembro de 2005. O Step 2, além de entrar na categoria de subsídio acionável, também foi condenado enquanto subsídio proibido (WTO, 2010c).

Vencidos os prazos para que os EUA dessem cumprimento às decisões do SSC, o Brasil solicitou, em dois pedidos separados, apresentados em julho e em outubro de 2005, autorização para retaliar em um montante total de cerca de US\$ 4 bilhões. No entanto, com a indicação de que poderia haver avanços no processo de implementação da decisão por parte dos EUA, o Brasil concordou em suspender os procedimentos de arbitragem iniciados para definição dos valores de retaliação. Até o momento, as medidas de implementação estadunidense, no que se refere aos subsídios acionáveis, limitam-se à eliminação do programa Step 2, a partir de agosto de 2006. Os principais programas de apoio interno, Marketing Loan e Counter-Cyclical Payments, permanecem intocados. Com relação aos subsídios proibidos, além da revogação tardia do Step 2, o governo estadunidense promoveu mudanças administrativas na operação dos programas de garantias de crédito à exportação e encaminhou à consideração do Congresso uma proposta que, em tese, possibilitaria tornar os prêmios cobrados para tais programas mais condizentes com seus custos e com a realidade do mercado (WTO, 2010c).

Diante do escopo limitado das medidas de implementação adotadas pelos EUA e havendo 
transcorrido cerca de um ano dos prazos estabelecidos para cumprimento das determinações do SSC, o Brasil decidiu solicitar a conformação de um painel de revisão na OMC para examinar a adequação do processo de implementação levado a cabo pelo governo estadunidense.

No segundo semestre de 2009, a OMC autorizou o governo brasileiro a adotar medidas de retaliação e exercer seus direitos compensatórios em função das práticas de subsídios à produção do algodão por parte dos EUA. O Brasil efetivará seus direitos adquiridos com a referente decisão, aplicando aos EUA uma gama de medidas de retaliação comercial, que podem chegar ao montante de US\$ 750 milhões ao ano e que só cessarão com a eliminação dos subsídios do governo estadunidense a commodity.

\section{CONCLUSÃO}

O presente artigo analisou a adoção de medidas de retaliação no exercício de direitos compensatórios à prática de subsídios no comércio agrícola internacional por meio de um levantamento em relação à evolução das diferenças comerciais submetidas à OMC. Foi possível identificar os EUA e a UE como as nações que mais utilizam os subsídios no comércio internacional, haja vista a quantidade de casos registrados na OMC que envolvem as duas nações como parte demandada em matéria de direito compensatórios à prática de subsídios. Em matéria agrícola, ostentam a posição de nações que mais usam formas de subsídios à produção e à exportação e foram derrotadas na OMC em dois casos emblemáticos para o setor e que envolveram o Brasil como principal beneficiário das decisões. Portanto, constatou-se que, tanto os estadunidenses quanto o bloco europeu são os membros que mais sofrem medidas de retaliação na OMC, em razão dos impactos de suas políticas de intervenção governamental protecionistas na forma de subsídios, completamente contrárias à liberalização comercial defendida pelo órgão.

Importante tratamento foi dado aos dois casos mais relevantes para os EUA e para a UE, submetidos ao SSC, da OMC, e que envolvem a concessão de subsídios na atuação dessas economias no comércio agrícola internacional. No caso dos subsídios da UE à exportação de açúcar, demonstrouse que o bloco europeu não vem diminuindo o nível de subsídio ao setor como determinou a decisão favorável ao Brasil, o que tem levado a nação brasileira a considerar uma possível solicitação junto à OMC de medidas de retaliação em razão do descumprimento da referida decisão. No caso dos subsídios à produção e à exportação do algodão estadunidense, verificouse que, no segundo semestre de 2009, a OMC autorizou o governo brasileiro a exercer seus direitos compensatórios em função da prática de subsídios à agricultura do algodão por parte dos EUA. O Brasil foi autorizado a efetivar seus direitos adquiridos com a referente decisão, aplicando aos EUA uma gama de medidas de retaliação comercial. A principal delas é a imposição de tarifas à importação, que podem chegar ao montante de US\$ 750 milhões ao ano e que só cessarão com a eliminação dos subsídios do governo estadunidense ao setor. No entanto, a ação está suspensa desde 2010, por conta de um memorando de entendimento entre os dois países, com as sanções sendo postergadas até que os EUA definam a sua nova legislação agrícola.

Entretanto, a não aplicação das retaliações pelo Brasil nos dois casos examinados e a manutenção dos subsídios pelos EUA e UE, tornaram inócuas as decisões da OMC, no sentido de eliminar o poder distorcivo da prática dos subsídios. De qualquer forma, a tendência é que as decisões da OMC continuem, no sentido de retaliar a prática de subsídios no mercado mundial, fazendo com que as discussões da Rodada Doha tenham sequência, sejam ampliadas e que resultem na adoção de políticas comerciais mais justas à agricultura e seu atual contexto de importância estratégica para as nações. É sob esse contexto que a questão dos subsídios concedidos à agricultura tem sido discutida em Doha, sendo que o Brasil vem atuando como líder do Grupo Cairns e como principal força econômica contrária a essa prática prejudicial ao equilíbrio do comércio mundial.

\section{AGRADECIMENTOS}

André Zago Azevedo é bolsista em produtividade do Conselho Nacional de Desenvolvimento Científico e Tecnológico (CNPq).

\section{REFERÊNCIAS}

BECHARA, C.H.T.; REDENSCHI, R. A solução de controvérsias no Mercosul e na OMC: o litígio Brasil x Argentina no Mercosul, o caso Embraer na OMC - Brasil x Canadá. São Paulo: Aduaneiras, 2001. 138p.

COSTA, C.C. da; BURNQUIST, H.L. O subsídio cruzado às exportações de açúcar da União Europeia: impacto sobre as exportações brasileiras de açúcar. Economia Aplicada, Ribeirão Preto (SP), v.10, n.1, p.91-109, 2006.

DANTAS, A. Subsídios Agrícolas: regulação internacional. São Paulo: Saraiva, 2009. 416p.

DURAIAPPAH, A.K. Trade-related subsidies: briefing the north-south divide. Geneva: IISD, 2003. 16p. 
LAFER, C. A OMC e a regulação do comércio internacional: uma visão brasileira. Porto Alegre: Livraria do Advogado, 1998. 168p.

LAMY, P. We renew our resolve to complete the Doha work programme fully and to Conclude the Negotiations Launched at the Doha Successfully in 2006. World Trade Organization Noticies - DG, Pascal Lamy, 24 dez. 2005. Disponível em: <http:// www.wto.org/english/news_e/sppl_e/sppl03_e.htm>. Acesso em: 15 out. 2011.

WORLD TRADE ORGANIZATION. Understanding the World Trade Organization. Geneva: WTO, 2011. 113p.

WORLD TRADE ORGANIZATION. DS265. Export subsidies on sugar. Geneva: WTO, 2010a. Disponível em: <http://www. wto.org/english/tratop_e/dispu_e/cases_e/ds265_e.htm>. Acesso em: 17 jul. 2012.

WORLD TRADE ORGANIZATION. DS266. export Subsidies on sugar. Geneva: WTO, 2010b. Disponível em: <http://www. wto.org/english/tratop_e/dispu_e/cases_e/ds266_e.htm>. Acesso em: 17 jul. 2012.

WORLD TRADE ORGANIZATION. DS267. Upland cotton. Geneva: WTO, 2010c. Disponível em: <http://www.wto.org/ english/tratop_e/dispu_e/cases_e/ds267_e.htm>. Acesso em: 19 jul. 2012.

WORLD TRADE ORGANIZATION. DS283. Export subsidies on sugar. Geneva: WTO, 2010d. Disponível em: <http://www. wto.org/english/tratop_e/dispu_e/cases_e/ds283_e.htm>. Acesso em: 17 jul. 2012. 